\title{
Use of a social network class: an alternative to engage learners
}

\author{
Danielle M. Bebey \\ DICEN-IDF, France, daniellebebey@gmail.com, ORCID 0000-0001-9524-6916
}

\begin{abstract}
This document presents the modelling and engagement process that emerge from content creation on a social network device. The latter is used informally and collaboratively to provide a meaningful learning environment and to constitute the distant side of a blended learning. This device puts into perspective the use of social network that can be beneficial for training. It also shows a creative approach to a mediation initially designed for entertainment. This is an action research project conducted in the form of grounded theory in the context of a communication course. The results of this research make it possible to understand the stakes of distant social experience on training. They are useful to the trainer through the conceptual modelling of processes. They are also useful for research that addresses training issues such as engagement through information and communication technologies. We finally see that this device can serve as a springboard for more immersive technologies such as artificial intelligence.
\end{abstract}

Keywords: collaborative learning; informal learning; experiential learning; adult learning; distance learning

\section{Introduction}

We have postulated that face-to-face learning does not always facilitate monitoring. The sheer presence of the learners is no longer sufficient to express a commitment. The intensity of the investment reflects the intensity of the motivation that represents an individual's commitment (Duchesne \& Savoie-Zacj, 2005). Engagement reflects the active involvement of an individual in a task or activity. The notion of engagement is therefore both psychological and attitudinal (Macey \& Schneider, 2008). It also has an existential dimension. In the constructivist sense, learning is a voluntary activity of information seeking that maintains social interactions and conditions the transfer of skills (Jouquan \& Bail, 2003). The learning objective is to make the learner progressively autonomous. To do this, the training team must be involved and also committed to this project (Presseau, 2000).

It is for this reason, among others, that blended learning is recommended to add the collective dimension that is missing from the classroom sequences. To this end, digital learning management systems such as Moodle or Sakai have been developed. It has been shown that the collective learning dimension also influences the commitment to distant learning (Chachkine, 2012). Researchers have been observing a renunciation of beneficiaries regarding those institutional systems (Peraya \& Bonfils, 2012). Therefore, other devices have been developed, which lead to twittclasses, ${ }^{1}$ Facebook class groups, identified in the work by Aaen \& Dalsgaard (2016) and Cottier \& Person (2018), MOOC and other derivatives such as $\mathrm{COOC}^{2}$ or SPOC. ${ }^{3}$

Some are open source, increasing the distance between stakeholders and not reducing the management of the learning community. Others, more restricted, propose either a prescribed use (Ros, 2018), which corresponds to the recommendations of information research without distinction of the functionalities and specificities of the technology, or an observed use (Cottier \& Person, 2018) where the access to groups built and managed by the sample observed without the intervention of the trainer is given to researchers (Aaen \& Dalsgaard, 2016). Following our observations of the existing system, we imagined the "Facebook class". This virtual class applied on Facebook is a closed or restricted group, activated to develop a collaborative pedagogy. The spirit of a classroom is repatriated and diverted into this social network class. This system differs from its predecessors in that the teacher-researcher is integrated into transactions as in a physical class. The training in this class promotes the use of a platform, with multiple functionalities and part of the daily life of users. Several classes can be considered around other networks such as WhatsApp or

\footnotetext{
${ }^{1}$ Twittclasses: a form of learning developed on the social network Twitter.

${ }^{2}$ COOC: corporate open online courses.

${ }^{3}$ SPOC: small and private online courses.
} 
Google as was the case with Classroom on Google Plus, hence the name "social network class". In this paper, we present the model applied with one group of higher education learners living in France and the impacts of this approach on their training.

\section{Conceptual design}

Table 1. Conceptual modelling: adjustment of Meirieu's models (reproduced by Brodin, 2002).

\begin{tabular}{ll}
\hline \multicolumn{1}{c}{ Model Poles } & \multicolumn{1}{c}{ Description } \\
\hline Stakeholder involvement & $\begin{array}{l}\text { The teacher: online community manager, interaction analysis, planning of empowering } \\
\text { sequences, evaluation of contributions } \\
\text { Learners: research, sharing and appreciation of mediatized information } \\
\text { Choice of the free connection tool, mobile participation, free contribution space. }\end{array}$ \\
Technical device & $\begin{array}{l}\text { Collaborative class for } 4 \text { months, complementarity of technologies and learning (transmedia } \\
\text { character) }\end{array}$ \\
Godel specificity & $\begin{array}{l}\text { Social interaction, engagement, collective intelligence, located and distributed cognition } \\
\text { Strategic learning areas }\end{array}$ \\
$\begin{array}{l}\text { Enrichment of the course seen in the classroom, intrapreneurship, learner-centred learning, } \\
\text { development of transversal skills, development of communication skills. }\end{array}$ \\
$\begin{array}{l}\text { Frequent practices observed } \\
\text { over the period }\end{array}$ & $\begin{array}{l}\text { Assessment of the session summaries } \\
\text { Sharing text data } \\
\text { High engagement rate for the } 2 \text { days following the face-to-face session }\end{array}$ \\
\hline
\end{tabular}

In this model, we focused on important and reusable poles. The possible learning spaces are numerous: computer room, classroom, personal devices such as computers, tablets or mobile phones and even home computers. The temporality of the contribution is free, depending on the medium adopted. One of the limitations encountered by distance learning practitioners is the restrictions of feedback, learners' actions and behaviours (George, 2004). Facebook classifies the following through the social network: the tracks of the behaviour, activities or actions of learners in distance learning situations. According to the literature, the social network unanimously appears as an important educational tool to receive help and support. The tool is validated as another learning space where personal, social and professional life overlaps with educational life. In this virtual class, this educational life is applied as informal (Chen \& Bryer, 2012) and asynchronous learning (S. R. Hiltz, 1998; S. Hiltz \& Wellman, 1997) to enrich the formal learning.

We propose an immersive environment as defined by Bonfils (2014), which is already anchored in the uses and which takes into account the four communicative spaces such as the physical space, the digital space, the space of possible or potential reception and the space of the action or potential of the emission. In the social network class, the physical space is implied. The description of the conceptual model of this informal learning presents the hybridization of a device that reveals a deconstructed side of traditional learning. The learning situation is real and matured. The literature committed is to strengthen the model. The latter is used here to present the communication situation that led to our observation of the engagement in this device.

The model proposes an evolutionary operating method. It is a learning method that takes into account the learners' skills, disciplinary, social and other contexts. Thus, the teacher's individual training path will have a strong influence on the form and quality of his or her training and consequently on the commitment of his or her learners. The asynchronous or semi-synchronous nature of the device reinforces this alteration but does not distort the experience (Cottier \& Person, 2018). We hypothesize that this type of device (informal and collaborative) contributes to increasing the participation of learners so as to lead to a commitment in situated relationships. The challenge was to gain support when the use differs from its origin. We choose to apply the principles of hybrid learning as presented by Valdès (1995; 1996) and mentioned by Charlier, Deschryver, \& Peraya (2006). It is a mechanism that contributes to consolidating learner-centred learning by following negotiated paths, an individualized pace, multiple places, decentralized and distance-accessible resources, adapted pedagogical situations, diversified and adapted media, individualized pedagogy. This form of learning helps to generate interaction and channel it within the group.

It complements classroom learning and promotes the creation of links between learners and appears as a continuum of pre-existing relationships in the physical classroom, as Perea (2011) suggested. We apply the basic university education configuration proposed by Charlier et al. (2006). The only difference is that workload distribution is not imposed. The estimated ratio is at least 20/80. Once again, participants are given some freedom of action to give free rein to their imagination and to a gradual immersion. It is also an opportunity to practise reverse virtual class, i.e. to paraphrase (Bergmann \& Sams, 2014). Thus, learners will deepen the concepts learned in class and share them in virtual classrooms (Sidir, Lucas, \& Giguet, 2006). This will make it possible to assess the level of understanding, demand and relevance of the information collected in addition to strengthening the relationship between stakeholders. The aim is to involve them more in their learning and at the same time to collect the information necessary to guide 


\section{Use of a social network class, an alternative to engage learners \\ Bebey}

them towards a situated relationship commitment. There is both a relationship and communication situations that suggest a form of relationship engagement located in this device.

This form of learning solves some of the problems identified by Vanpee, Godin, \& Lebrun (2008). The learner can come back to the shadow areas of his learning. He is no longer left to his own devices in his evolution and can even reach the same level of understanding as the rest of the group. The most advanced have the opportunity to accompany others and can be inspired by other media to enrich discussions within the classroom. This part of the blended learning highlights several dimensions of Khan's (2005) octagonal framework cited by Singh (2003). It integrates the institutional (administrative: course programming, tools made available, etc.); pedagogical (scenario by pedagogical objective); technological (security, software, technical prerequisites); interface design (practical feasibility); evaluation; management; support resource (offline, hardware, software, human and possibly financial) and ethical (protection of personal data, principles, etc.). The objective is to provide an original learning experience for the learners, as proposed by Garrison \& Kanuka (2004).

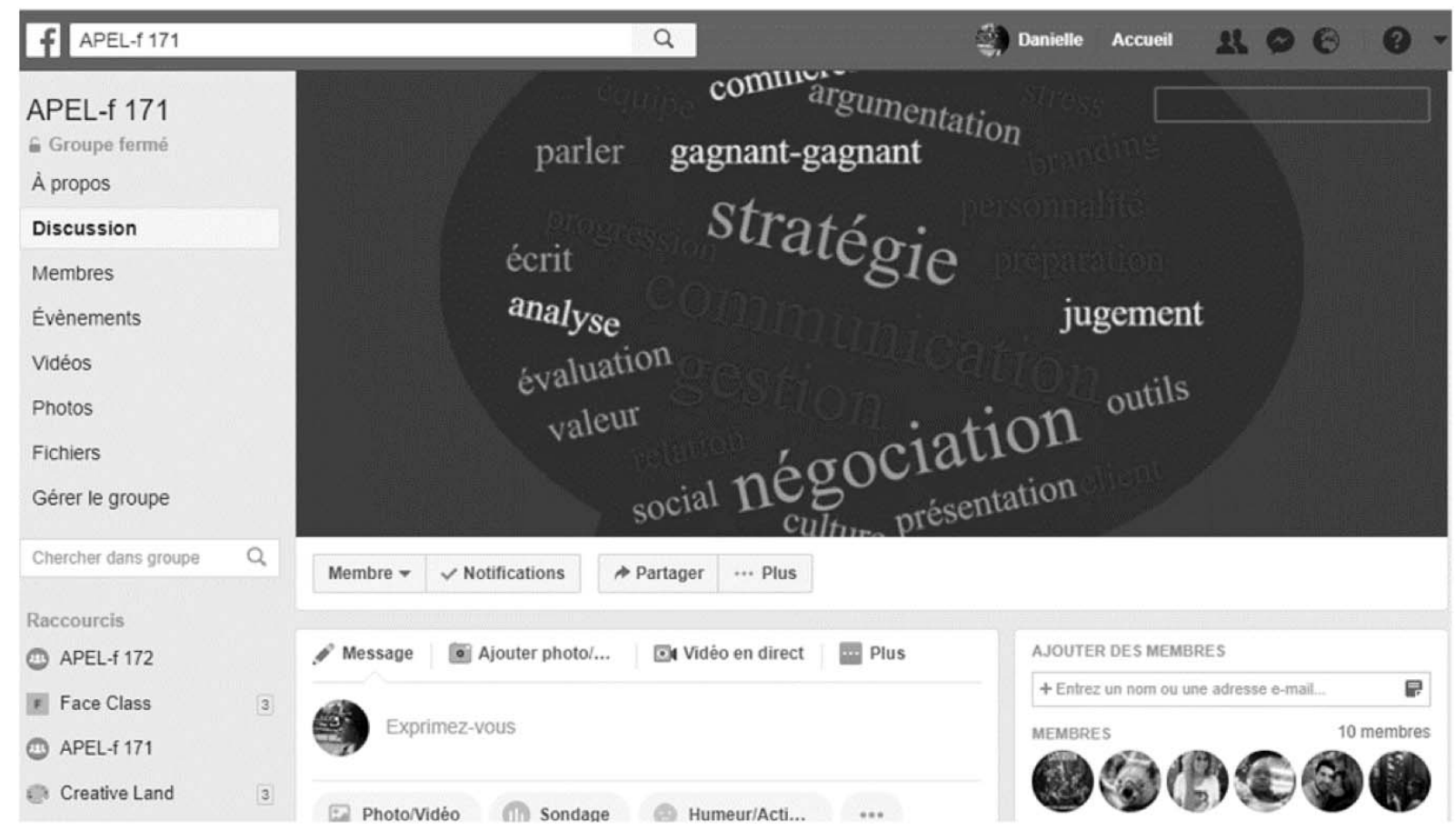

Fig. 1 The Facebook class.

\section{Experiential research}

\subsection{Sample}

The population of this social network class has only been confronted with social networks since adulthood, which has recently been implied. It does not have the same autonomy as the digital native or Y generation. Some do not even have a Facebook account. Others do not know its functionalities or are more or less active or automatically associate it with a "given catch". The particularity of this group is that it is essentially constituted of professionals working in various fields (health, sports, medico-social). The audience in this class is between 25 and 45 years old. The sample is therefore made up of adults, and the identification of profiles is based on the questionnaire. We have a majority of women $(80 \%)$ in this class of ten learners. Those who had a Facebook account $(70 \%)$ before the social network class used it privately, and the majority (70\%) used it on their mobile phones. This research was carried out at the CNAM Ilede-France4 as part of a communication course attached to the RNCP Level III5 Title, in charge of social and professional support. The face-to-face sessions were held for 3 hours on Thursday, from October 2017 to January 2018.

\subsection{Data collection}

The observation of learners' discussions on this collaborative platform is carried out continuously over a period of 4 months. It is associated with informal conversations, a face-to-face group interview, recorded and shared on the

\footnotetext{
${ }^{4}$ CNAM Ile-de-France: national conservatory of arts and crafts, a school in the Paris region.

${ }^{5}$ RNCP: national repertory of professional qualifications.
} 
virtual classroom for confrontation and a questionnaire to establish a triangulation of data from a scientific point of view. Added to the questionnaire, we use a Facebook group analysis tool: Grytics. The questionnaire administrated via Google Drive included 12 categorical variables such as civility, age and vocational category or business area that described our statistical units. The questions were indirect with direct or indirect interpretations depending on the indicator being evaluated. The quantitative variables studied were continuous, because they were represented by frequencies. While qualitative variables are nominal because they present points of view and ordered because they highlight value scales.

The descriptive quantitative approach is present in this part of the research. The qualitative interpretation is based on Paillé's (1994) anchored theory analysis. To avoid the pitfalls of action research conducted by the grounded theory of Garreau \& Bandeira-De-Mello (2010), we take into account the indicators already identified in the literature, particularly interactions, satisfaction, etc. We add other relevant indicators that apply to our study. The interpretation, analysis and representation of the interview data were performed with the Iramuteq tool (Chaves, Santos, Santosa, \& Larocca, 2017) for a visualization of textual data and an analysis of word networks. It deepens the different approaches to deductive corpus analysis that allow the research hypothesis to be tested. We present some screenshots of this triangulation.

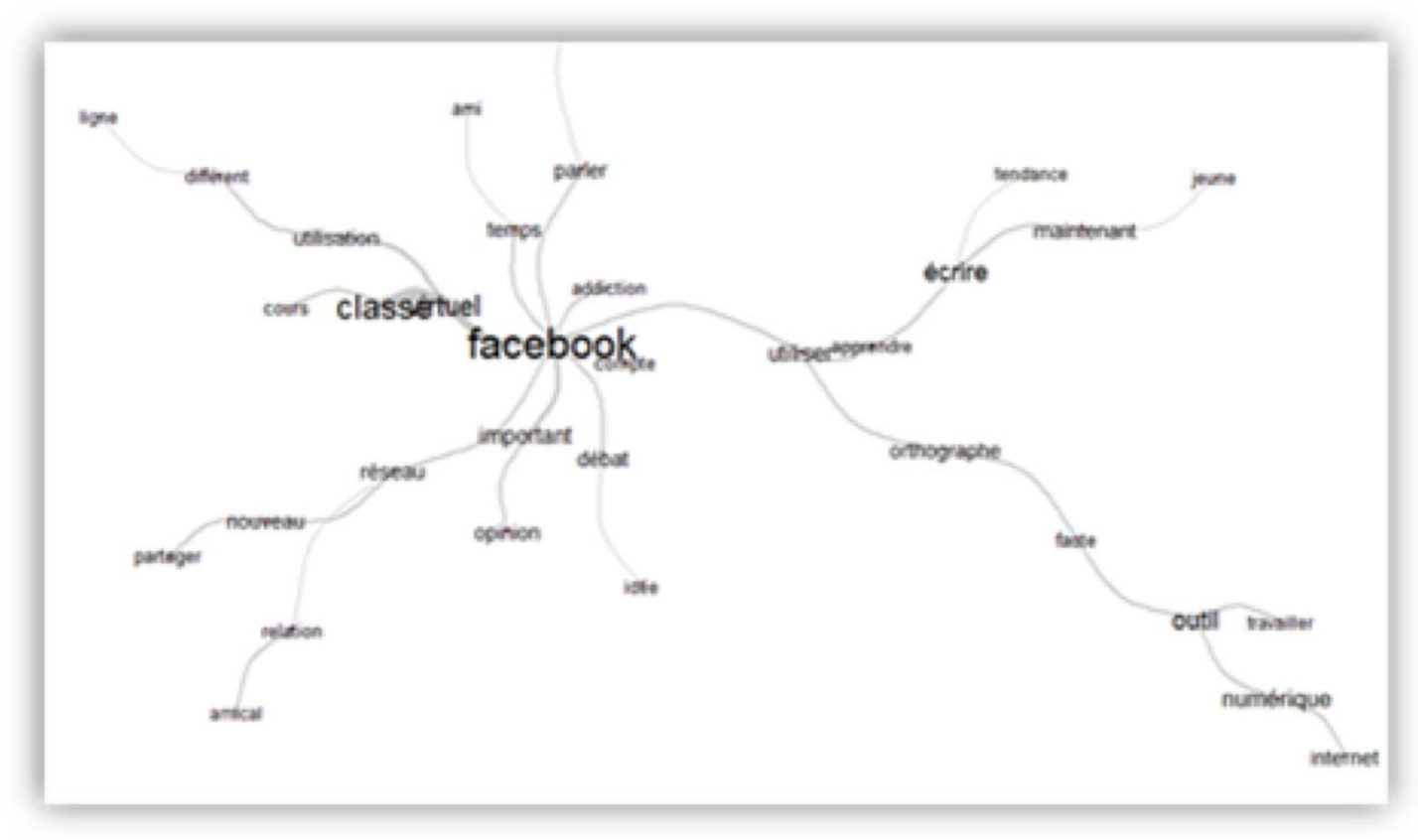

Fig. 2 Iramuteq information

This figure identifies the networks of words used in this interview. They will help the reader to better understand our interpretations. Words with a large font are the most common. In the same way, the most imposing branches materialize the strong connection. The tree structure reflects the associations that were made during the speech. The number of shapes is 642 .
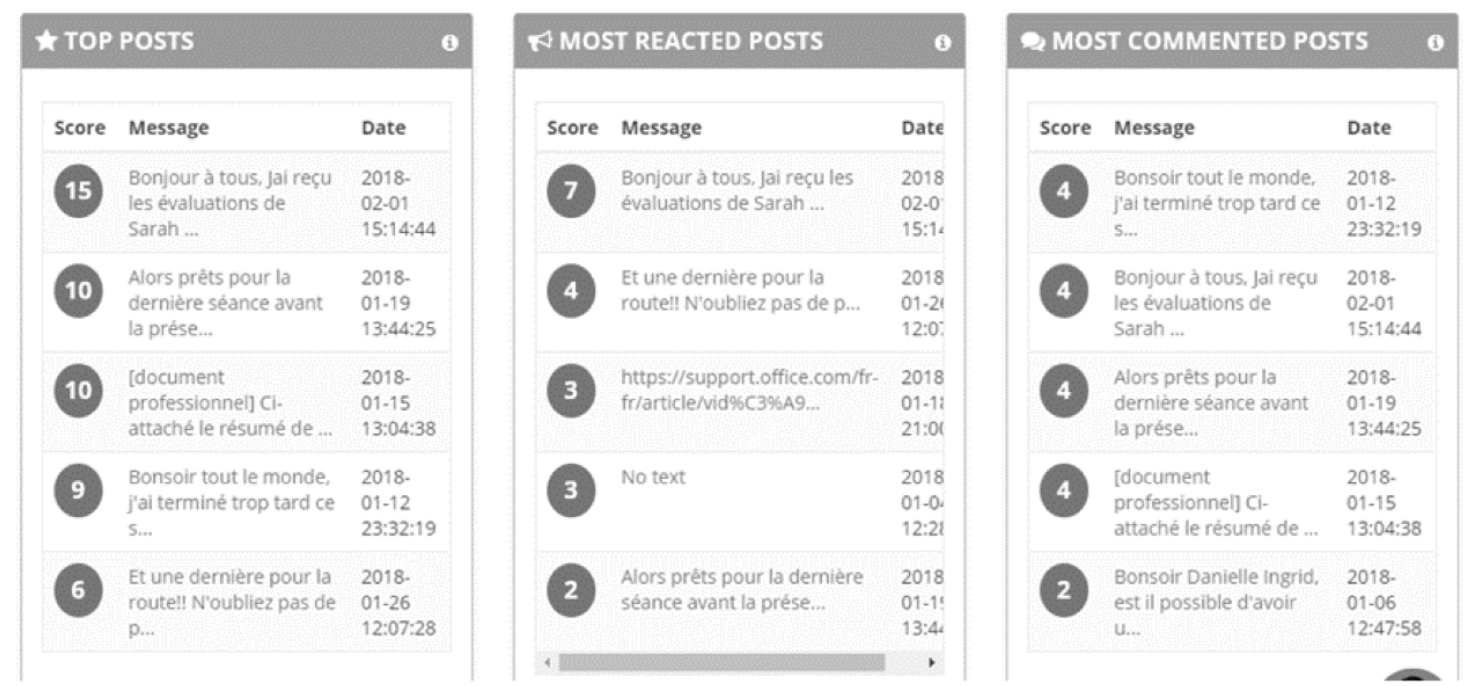

REM - Research on Education and Media. Vol. 11, N. 1, Year 2019 - ISSN: 2037-0830 
Fig. 3 Learners' reactions.

We notice on these results that learners reacted more to peer messages or messages that were not directly related to the course. We note a strong commitment to these messages.

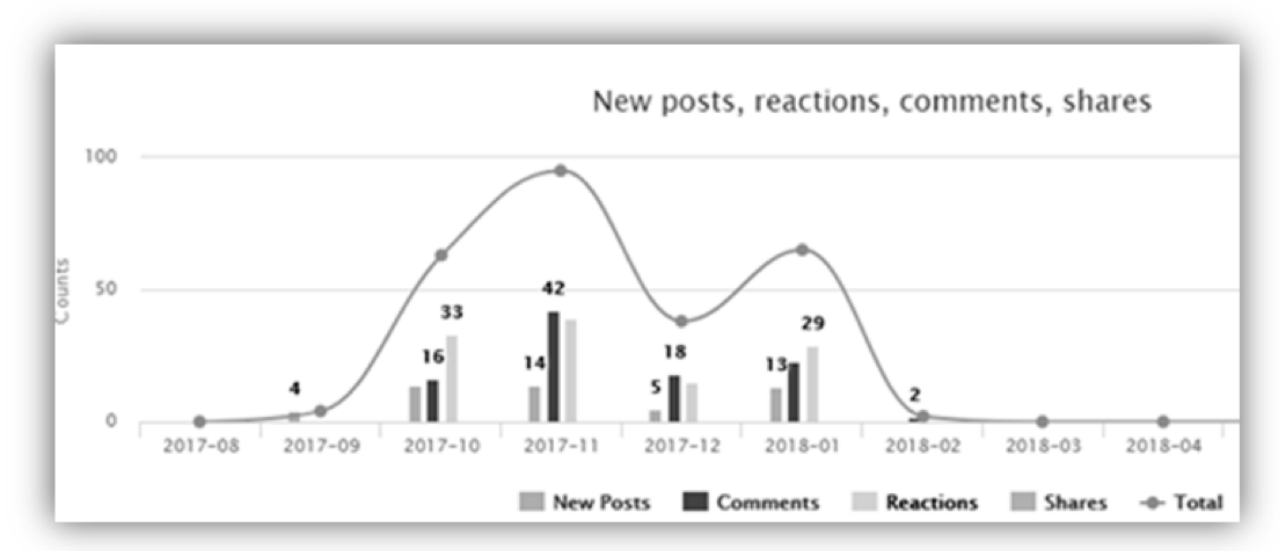

Fig. 4 Grytics information.

We can see, through this graph, a fluctuation of interactions within the virtual classroom. The socio-digital class for learners was created at the end of September 2017. We notice a progressive evolution of the activity through comments, reactions and posts. As the class is inactive during the end-of-year holidays, we observe a drop-in traffic that resumes

\section{Q Comparaison de statistiques}

\begin{tabular}{|c|c|c|c|}
\hline & 2017-09-30 to $2017-10-31$ & 然 $2017-11-01$ to $2017-12-31$ & Evolution \\
\hline \multicolumn{4}{|l|}{ Général } \\
\hline Activité & 1.5 & 2.43 & $62 \%$ \\
\hline Engagement & 4.82 & 8.45 & $75.31 \%$ \\
\hline Posts créés & 11 & 22 & $100 \%$ \\
\hline Commentaires & 16 & 60 & $275 \%$ \\
\hline Réactions & 21 & 66 & $214.29 \%$ \\
\hline \multicolumn{4}{|l|}{ Posts } \\
\hline Posts avec réactions & 9 & 20 & $122.22 \%$ \\
\hline Posts commentés & 3 & 17 & $466.67 \%$ \\
\hline $\begin{array}{l}\text { De publications avec réactions, } \\
\text { commentaires ou partages }\end{array}$ & 9 & 21 & $133.33 \%$ \\
\hline
\end{tabular}

timidly until the end of the training in early February 2018.

Fig. 5 Evolution of engagement scores from Grytics.

We observe a commitment of 8.45 points with a $75.31 \%$ increase. Learners' reactions have increased by more than $200 \%$ and commented posts by more than $400 \%$. Without the interruption of the holidays, the activity would certainly have continued to grow. Nevertheless, we were able to observe a commitment score that almost doubled in this socionetwork class.

To this question, all respondents rated the relevance of the socio-network as being 5/10 or higher in their training. 


\title{
Comment évaluerez-vous la pertinence de cette classe virtuelle dans votre formation?
}

\author{
8 réponses
}

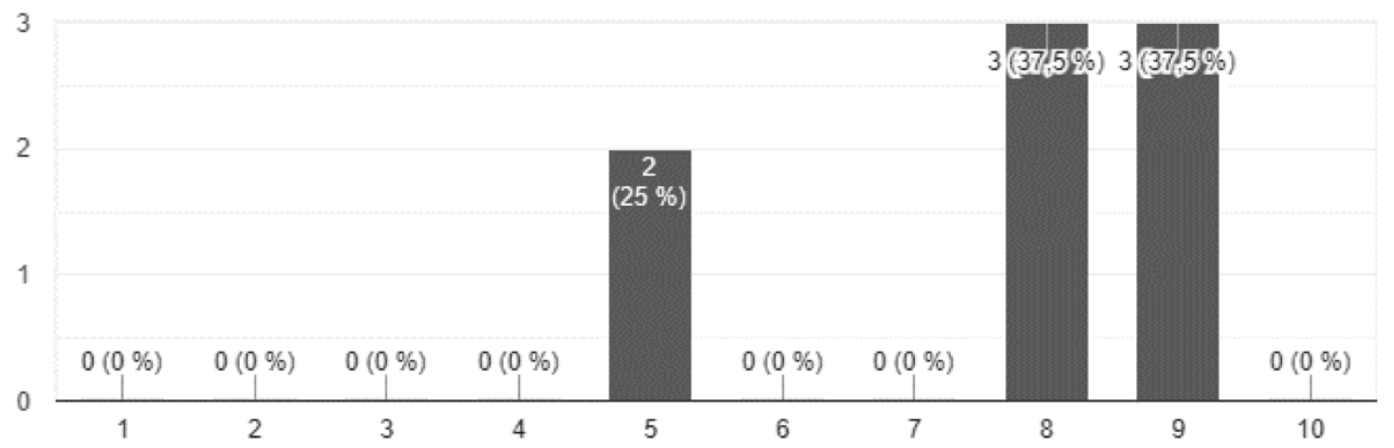

Fig. 6 Relevance evaluation of the proposition by learners from Google form.

\subsection{Data privacy}

Another important aspect recognized by researchers (Cottier \& Person, 2018) is the possibility of managing the confidentiality of data on the social network. One of the means we put in place at the beginning is the group restriction. Apart from registered users, no member of the Facebook community can receive suggestions about our group unless they have their username. Here again, knowing the identifier certainly offers the possibility of establishing an application for membership but does not guarantee the acceptance of the administrator. We keep almost the same confidentiality as the physical space. The use of scientific data also respects this ethics.

\subsection{Analysis}

In this experience, the indicators identified are distant human interaction, social performance (satisfaction, relevance) and/or empowerment (awareness). From a methodological point of view, the observation of interactions makes it possible to identify the forms of engagement or ultimate participation of the group studied. Indeed, if we stick to the statistics of the Grytics tool, learners preferred the content shared by their classmates to that of the teacher. Their involvement in enriching the course helps to better understand their needs. This also allows those who are more advanced in training (more comfortable with communication and tools or with the course) to pass on knowledge to others through feedback. Reactions were also significant on content that was not related to the training. This indicates their need to escape or a desire to diversify activities outside the physical space of the course. The additional time to be allocated to learning, raised during the interview, requires constant flexibility of actions to be allowed. The learner was only able to get the most out of his investment if he perceived, at the right time, fewer constraints.

We evaluate the progression of the discourse in the group, the reactions to the different interventions, the preferences, in short, a form of engagement that emerges from this system. These observations are supplemented by the observation of learners' changes in the classroom. We can say that this mechanism has effectively contributed to the consolidation of the commitment to training of this group of learners. The majority of learners did not invest themselves out of obligation but because they finally perceived an interest. The results of the questionnaire demonstrated the learner consideration of this class. A significant majority found this proposal relevant for their training with a score above $5 / 10$. The social network class therefore brings a new form of use that highlights the innovative nature of an experience. We note an expression from one of the respondents along these lines: "The virtual classroom was an innovation", "it's a discovery". However, this experience was confronted with some difficulties, in particular the difficulty of interaction with unknown people in real life or the difficulty of understanding the instructions. In view of the results obtained with regard to the relevance of this proposal, we believe that the experience was mostly positive for the most part. The social performance, especially relevance, confirms it.

This system was considered decisive in the memorization of courses and the involvement of learners. Indeed, participation in Facebook class was not mandatory, some registered late. In the end, they appreciated it by giving high 
scores. Thus, $75 \%$ of the sample perceived relevance. This form of participation was certainly appropriate for their schedules because the visualization of schedules and days of participation was significantly dispersed throughout the week and day. A large majority made a value judgment on the experience of the Facebook class. For them, it was a "different way of learning", to break the "classical distant" format, to develop "a great openness to the world", to "see its progress" and to "bring listeners closer", in short, an "interesting discovery". Through the Grytics application, we notice a commitment score that increases over time in a regular learning rhythm. This device offered an innovative experience to learners. The innovation paradigm identified shows their awareness.

Regarding occurrences noted by Iramuteq, they considered this class as a tool, an innovative and important proposition, for work, to share opinions and develop amical relationships via the Internet. Their behaviour also evolved from the beginning. They have gone from a difficulty in communicating with unknown people to a need to establish friendly relationships. The sociological paradigm of an experience comes out.

In terms of inputs, as learners mentioned in the interviews, the social network class is a tool that can be used to its advantage. We use quotations that detail this idea: "I will say that these instruments are important, if we want to learn more; whether it is spelling mistakes or other. And if we want, we use it as we wish";" it's a tool! "Yes!" It's a tool! It means that it can be an advantage or a disadvantage. It depends on how you use it";" and if you want to write correctly, you can too". Like any instrument, the social network class has some barriers that learners have also identified. These include the problem of "addiction"; the fact that some people "fall into the easy" because they passively wait for others to react.

We also observe a change in interactions between individuals. Thus, in just 4 months, we went from 0 to 105 comments and from 0 to 116 reactions or 91 likes of comments in the group with ten learners. The learning situation developed to strengthen relationships allows us to achieve the expected effects. The interactionist paradigm surveyed demonstrates the evolution of interactions among the learner group.

The relational aspect was manifested through the exchange of information, the manifestation of affect (comments, reactions) between stakeholders. Learners and the trainer remained in contact for a period beyond the duration of the course in a physical space through this device. In the sense of Zacklad (2012), there are 2 forms of engagement which are the engagement in relation and the engagement through communication situations. These two forms materialize together in this system, which is why we speak of a commitment in a situated relationship. In an informal distance learning situation, interactions between stakeholders contribute to strengthening the links between individuals and contribute to the enrichment of knowledge. Learners are conscious of the changes and validate the relevance of the proposition.

\section{Perspectives}

Although adults, learners observed adhere to this technology. For minor learners, whose parental consent is sought, we agree that monitoring of learning in the digital work environment should be developed. As a first effort, a system of anonymization of learner profiles can be deployed over the duration of a teaching unit, for example. This would be an opportunity to involve other human resources (parents, professional actors) in the pedagogy.

It was important to explain the issues of such an experience to the trainer, the learner, the end user and the administration. In a managerial sense, this approach focuses on the user's experiential satisfaction.

The configuration tools can define the trainer as the group administrator to supervise transactions. Although the objective is to promote discussions among other things and to obtain means of monitoring with a minimum of transparency, the social network class does not constitute a barrier to learning. Learners are inspired by open platforms, and summaries of face-to-face sessions are resumed in virtual classrooms, in addition to other information.

The visualization of data specific to this virtual class shows a decrease in engagement during the end-of-year holidays and an increase when classes resume. This confirms the theory that commitment is materialized not only by the situation of effect but also by constantly soliciting attention. Moreover, being more accessible, this device can be a gateway for immersive environments still in the experimental stage. Such a system provides a greater involvement of social network in the human sciences, knowing that some are already involved in applied research through artificial intelligence.

This approach requires skills in project management, community management on social networks in addition to the preparation of pedagogical scenario. The trainer must therefore make an extra effort or surround himself with a highperformance team. The limits of collaborative asynchronous learning identified, such as the distance between stakeholders, the loss of time spent in training stakeholders on the tools and the diversion of the educational aspect of the tool, are measured in our system. The implementation of the system more as a space for sharing than a classical course demystifies discussions. The distance finally brings the learners closer. Since we cannot explore all the perspectives of this system, we open the discussion regarding the application of such a proposal for training, from countries with different contexts and cultures. Nevertheless, the observations collected make it possible to identify whether the digital document of the Facebook class type contributes to the participants' situated relationship engagement. 


\section{Conclusions}

New technologies, which require a learning period, are not necessarily accessible to the public. Facebook is free. In addition, it is also a way to engage in relationships. We think it is a way to prepare users for more immersive technologies. This paper answered the question of how to create digital content. Teachers are not necessarily required to be a computer developer. They can define their objective, with a commitment with innovative medium. Then, they model their user-centred scenario to get a baseline for their community management via a tool that originally engage learners. In a blended learning approach, this informal class complements the formal physical class and offers learners the opportunity to strengthen their bonds while learning. This is what cognitians call spealth learning. We say that the learners have finally become aware of the relevance of this class.

In addition, the automation of data collection, which is being developed via bots or artificial intelligence on Facebook, will allow researchers to better understand and monitor learners' needs. This also allows time for the development of these technologies to make them easier to handle.

\section{References}

Aaen, J., \& Dalsgaard, C. (2016). Student Facebook groups as a third space: between social life and schoolwork. Learning, Media and Technology, 41, 160-186. https://doi.org/10.1080/17439884.2015.1111241

Bergmann, J., \& Sams, A. (2014). Flipped Learning: Gateway to Student Engagement. International Society for Technology in Education.

Bonfils, P. (2014). L'expérience communicationnelle immersive: Entre engagements, distanciations, corps et présences (Thèse d'habilitation à diriger les recherches, Université Lille Nord de France (Université de Valenciennes et du Hainaut-Cambrésis).).

Brodin, E. (2002). Innovation, instrumentation technologique de l'apprentissage des langues : des schèmes d'action aux modèles de pratiques émergentes. Apprentissage des Langues et Systèmes d'Information et de Communication, 5(2), 149-181.

Chachkine, E. (2012). Scénario pédagogique responsabilisant. Les Langues Modernes, 3-2012, PP.12-17.

Charlier, B., Deschryver, N., \& Peraya, D. (2006). Apprendre en présence et à distance, Abstract. Distances et savoirs, 4(4), 469-496.

Chen, B., \& Bryer, T. (2012). Investigating instructional strategies for using social media in formal and informal learning. The International Review of Research in Open and Distributed Learning, 13(1), 87-104.

Cottier, P., \& Person, J. (2018). L'expérience lycéenne des réseaux sociaux numériques. Sociabilité et instrumentalisme en espace protégé. Distances et médiations des savoirs. Distance and Mediation of Knowledge, 2018(21). https://doi.org/10.4000/dms.2098

Duchesne, C., \& Savoie-Zacj, L. (2005). L'engagement professionnel d'enseignantes du primaire: une démarche inductive de théorisation. Recherches qualitatives, 25(2), 69-95.

Garreau, L., \& Bandeira-De-Mello, R. (2010). La théorie enracinée en pratique: vers un dépassement de la tension entre scientificité et créativité dans les recherches basées sur la théorie enracinée ? (p. 1-19). Présenté à AIMS 2010. Consulté à 1'adresse https://halshs.archives-ouvertes.fr/halshs-00580543/document

Garrison, D. R., \& Kanuka, H. (2004). Blended learning: Uncovering its transformative potential in higher education. The Internet and Higher Education, 7(2), 95-105. https://doi.org/10.1016/j.iheduc.2004.02.001

George, S. (2004). Analyse automatique de conversations textuelles synchrones d'apprenants pour la détermination de comportements sociaux. Sciences et Technologies de l'Information et de la Communication pour l'Éducation et la Formation (STICEF), Vol. 10, 165-193.

Hiltz, S. R. (1998). Collaborative Learning in Asynchronous Learning Networks: Building Learning Communities. Consulté à l'adresse https://eric.ed.gov/?idED427705

Hiltz, S., \& Wellman, B. (1997). Asynchronous Learning Networks as a Virtual Classroom (Vol. 40). https://doi.org/10.1145/260750.260764

Jouquan, J., \& Bail, P. (2003). A quoi s'engage-t-on en basculant du paradigme d'enseignement vers le paradigme d'apprentissage ? Pédagogie Médicale, 4(3), 163-175. https://doi.org/10.1051/pmed:2003006

Macey, W. H., \& Schneider, B. (2008). The Meaning of Employee Engagement. Industrial and Organizational Psychology, 1(1), 3-30. https://doi.org/10.1111/j.1754-9434.2007.0002.x

Paillé, P. (1994). L'analyse par théorisation ancrée. Cahiers de recherche sociologique, (23), 147-181. https://doi.org/10.7202/1002253ar

Peraya, D., \& Bonfils, P. (2012). Nouveaux dispositifs médiatiques : comportements et usages émergents. Le cas d'étudiants toulonnais en formation à l'UFR Ingémédia. Distances et médiations des savoirs. Distance and Mediation of Knowledge, 1(1). https://doi.org/10.4000/dms.126 
Perea, F. (2011). L'identité numérique : de la cité à l'écran. Quelques aspects de la représentation de soi dans l'espace numérique, Abstract, Resumen. Les Enjeux de l'information et de la communication, me 2010(1), 144-159.

Presseau, A. (2000). Analyse de l'efficacité d'interventions sur le transfert des apprentissages en mathématiques. Revue des sciences de l'\&\#233;ducation, 26(3), 515-544. https://doi.org/10.7202/000289ar

Ros, M. Z. (2018, février 22). Comment j'utilise les médias sociaux dans mes cours à l'université [Billet]. Consulté 29 mars 2018, à l'adresse https://red.hypotheses.org/1137

Sidir, M., Lucas, N., \& Giguet, E. (2006). De l'analyse des discours à l'analyse structurale des réseaux sociaux : une étude diachronique d'un forum éducatif. Sciences et Technologies de l'Information et de la Communication pour l'Éducation et la Formation (STICEF), 13, 20 pages.

Singh, H. (2003). Building Effective Blended Learning Programs. Educational Technology, 43(6), 51-54.

Vanpee, D., Godin, V., \& Lebrun, M. (2008). Améliorer l'enseignement en grands groupes à la lumière de quelques principes de pédagogie active. Pédagogie Médicale, 9(1), 32-41. https://oi.org/10.1051/pmed:2008032

Zacklad, M. (2012). Organisation et architecture des connaissances dans un contexte de transmédia documentaire : les enjeux de la pervasivité. Études de communication, 41-63. 